\title{
Playing with fire: an experiment in clinical budgeting
}

\author{
S M LAMB, T J DAVID
}

\section{Introduction}

Clinical budgeting is controversial. Many clinicians see a discrepancy between the motives of managers who want to make doctors more cost conscious and those of clinicians who want to make managers more aware of their real work. Some clinicians also fail to see why they should concern themselves in a function that they see to be the job of administrators. Others are happy to take part in the information gathering and administration of clinical budgeting, but think that there will have to be more doctors to enable this to take place. Notwithstanding this debate, the Griffiths report has recommended that systems of management budgeting should be implemented by district health authorities. In particular, there is a desire that clinicians should be included in this initiative, and clinical budgeting is currently being piloted at many sites throughout the country.

We recently completed a project to establish clinically meaningful budgets at Booth Hall Children's Hospital. This report outlines the results, along with the advantages and drawbacks of the method used.

\section{Method}

Patients were categorised into health care groups, a grouping of patients based on their clinical condition. This categorisation was done separately for each consultant and entirely depended on his particular case load. The 12 health care groups for one consultant are shown in table I. These groups accounted for $84 \%$ of this consultant's patient admissions. The remaining "miscellaneous" group of patients was disregarded in this study.

The clinician, initially the consultant paediatrician, was asked

\begin{tabular}{|c|c|c|}
\hline No & Health care group & $\begin{array}{l}\text { Cost } \\
(f)\end{array}$ \\
\hline $\begin{array}{r}1 \\
2 \\
3 \\
4 \\
5 \\
6 \\
7 \\
8 \\
9 \\
10 \\
11 \\
12\end{array}$ & $\begin{array}{l}\text { Asthma } \\
\text { Bronchiolitis } \\
\text { Croup } \\
\text { Respiratory infection } \\
\text { Viral illness } \\
\text { Febrile convulsion } \\
\text { Fever of unknown origin } \\
\text { Feeding difficulties } \\
\text { Failure to thrive } \\
\text { Poisoning } \\
\text { Eczema } \\
\text { Cystic fibrosis }\end{array}$ & $\begin{array}{r}229 \\
414 \\
114 \\
140 \\
89 \\
192 \\
231 \\
303 \\
354 \\
94 \\
1273 \\
1606\end{array}$ \\
\hline
\end{tabular}

\section{Deloitte Haskins and Sells, Manchester M1 4BX}

S M LAMB, BA, ACA, management consultant

\section{University of Manchester M9 2AA}

T J DAVID, MD, MRCP, senior lecturer in child health and honorary consultant paediatrician

Correspondence to: Dr David, Booth Hall Children's Hospital, Charlestown Road, Blackley, Manchester M9 2AA. to estimate what resources were used by the average patient in each group on his unit. For the health care group No 12, cystic fibrosis, the resources that were specified as an average requirement per admission are given in table II. A list like this was called a "resource recipe." To improve the accuracy of these resource recipes, other members of the team-such as registrars, senior house officers, nurses, physiotherapists, dietitians, medical illustrators-were also asked to estimate resource recipes. As a further method of cross checking, data were obtained directly from the intensive care unit admission book, the pharmacy records, and the pathology laboratory records to verify the resources actually used by a named medical firm.

TABLE II-Health care group 12 (cystic fibrosis): average resources consumed per admission

\begin{tabular}{|c|c|c|}
\hline Resource & Quantity & Units \\
\hline 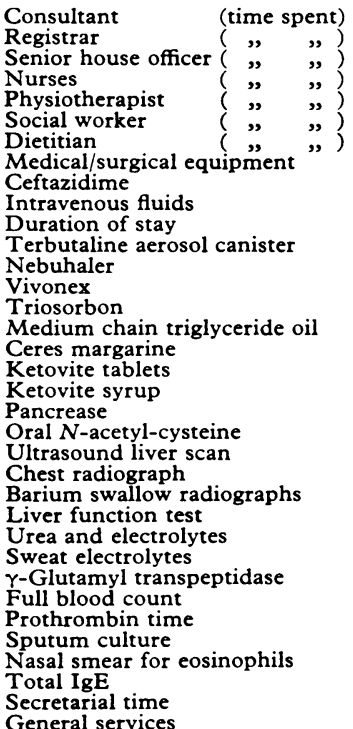 & $\begin{array}{l}6 \\
5 \\
10 \\
40 \\
28 \\
0 \cdot 1 \\
4 \\
10 \\
50 \\
240 \\
10 \\
192 \\
0 \cdot 8 \\
2 \\
6 \\
1 \\
2 \\
42 \\
70 \\
280 \\
6 \\
0 \cdot 5 \\
0 \cdot 75 \\
0 \cdot 02 \\
1 \\
2 \\
0 \cdot 04 \\
0 \cdot 1 \\
1 \\
0 \cdot 1 \\
10 \\
0 \cdot 05 \\
0 \cdot 15 \\
2 \\
10\end{array}$ & $\begin{array}{l}\text { Hours } \\
\text { Hours } \\
\text { Hours } \\
\text { Hours } \\
\text { Hours } \\
\text { Hours } \\
\text { Hours } \\
\text { Units } \\
\text { Grams } \\
\text { Hours } \\
\text { Days } \\
\text { Puffs } \\
\text { Units } \\
\text { Packets } \\
\text { Packets } \\
\text { Litre } \\
\text { Tubs } \\
\text { Tablets } \\
\text { ml } \\
\text { Capsules } \\
\text { Ampoules } \\
\text { Examinations } \\
\text { Examinations } \\
\text { Examinations } \\
\text { Test } \\
\text { Test } \\
\text { Test } \\
\text { Test } \\
\text { Test } \\
\text { Test } \\
\text { Test } \\
\text { Test } \\
\text { Test } \\
\text { Hours } \\
\text { Days }\end{array}$ \\
\hline
\end{tabular}

All recipes were costed using readily available budgeting and planning software operating on a microcomputer. ${ }^{*}$ For doctor and nurse time salary costs were divided between the health care groups according to the time spent with each category of patient.

Taking the total cost of consumable medical and surgical equipment (pharmacy staff salaries, bandages, dressings, needles, syringes, and so on) for the hospital, and taking the current budget statements as a measure of the relative usage between the specialties, an annual cost was derived for each specialty-for example, paediatric medicine. Costs were allocated between each health care group according to the duration of stay in hospital, and are listed as "Medical/surgical equipment" in table II. 
General hospital overheads, such as administration, staff catering, cleaning, portering, works, gardening, and so on, were calculated in a similar way and are designated as "general services" in table II. So a patient staying in hospital for 10 days consumes 10 "service days."

A further cross check on the accuracy of resource recipes and their costing was made. The number of patients treated in 1983, obtained from Hospital Activity Analysis statistics, and their case mix by health care groups was used, together with the resource recipes, to generate an estimate of the total bed/day occupation. This was then compared with the actual occupation for 1983 as recorded by Hospital Activity Analysis, with the result that predictive error was found to be less than $5 \%$.

This project was performed in conjunction with four consultant paediatricians, but this report is confined to the results of only one.

\section{Results}

The mean cost of treating patients in each health care group for one paediatrician based on 1982-3 prices (the latest locally available cost statements) is shown in table I.

The system was used to view the consequences of certain changes in treatment policy. Table III shows the number of patients treated as inpatients in 1983 and the clinician's forecast of those whom he expected to treat in 1985. This showed that, although there was only a small projected increase in the total number of admissions from 612 to $623(1 \cdot 8 \%)$, there was an appreciable change in the mix of patients. The system was then used to derive the consequences of such a projection with the recipe for the cystic fibrosis health care group amended to reflect a new treatment. An increase in the number of admissions of only $1.8 \%$ concealed the fact that this would entail an increase in bed/day occupation by $27 \cdot 2 \%$.

TABLE III-Case mix by health care group

\begin{tabular}{clcc}
\hline No & Health care group & $\begin{array}{c}1983 \\
\text { Actual }\end{array}$ & $\begin{array}{c}1985 \\
\text { Projection }\end{array}$ \\
\hline 1 & Asthma & 133 & 120 \\
2 & Bronchiolitis & 31 & 28 \\
3 & Croup & 41 & 37 \\
4 & Respiratory infection & 70 & 63 \\
5 & Viral illness & 39 & 35 \\
6 & Febrile convulsion & 37 & 33 \\
7 & Fever of unknown origin & 17 & 15 \\
8 & Feeding difficulties & 24 & 21 \\
9 & Failure to thrive & 53 & 48 \\
10 & Poisoning & 63 & 63 \\
11 & Eczema & 50 & 75 \\
12 & Cystic fibrosis & 54 & 85 \\
\hline & & 612 & 623 \\
\hline
\end{tabular}

\section{Discussion}

The results show that any system of budgeting based purely on specialty averages - for example, $£ 400$ per admission, regardless of what is wrong with the patient-would produce misleading information. A $2 \%$ increase in the number of patients would lead to the conclusion that there would be a $2 \%$ increase in costs. The results here show that a system sensitive to the case mix of patients is essential. A system like this may be used in three ways. It may be used to establish budgets for individual clinicians based on the resources required to treat their patients. Expected expenditure could then be compared with actual spending. Secondly, it may be used to determine the implications of changes in the case mix of patients or of new methods of treatment. Finally, it may be used for strategic long term planning of hospital services; the estimation of hospital resources that would be required after, for example, a demographic change in the catchment area. A drawback of this study is that only inpatient expenditure was examined, an important omission for a discipline such as paediatrics in which there is an increasing tendency to avoid admission and provide outpatient treatment.

This system offers the ability to allow for factors not covered by standard National Health Service reporting systems. Table II, for example, shows the need for secretarial time relating to hospital admission. In principle any item of cost could be brought within the recipes. In particular the costs of depreciation and capital maintenance could be included in the system. The problem with including items such as these, or the costs of nursing or doctoring, is that control of these items is not likely to be possible by an individual clinician except by reducing admissions, which in turn could lead to a reduction of beds and staff. In fact the single most important factor in determining the cost of health care groups was the length of stay in hospital.

The major work includes costing prescriptions in pharmacy and individual tests in the pathology laboratory, both of which are laborious even with computerisation. There are problems with using the figures for nursing time, which would be more accurate were they derived from patient dependency studies.

Conventionally, budgeting in the NHS is based on a "top down" approach. This means that a specific hospital's budget, like a cake, is divided into separate slices for nursing salaries, drugs, laboratory investigations, catering, and so on. The "bottom up" approach in this study is the reverse, for the starting point is the need for resources based on a case load and case mix.

The enormous costs for cystic fibrosis and eczema reflect the special interests of the consultant concerned. For cystic fibrosis, the availability of a new antibiotic, ceftazidime, has rapidly altered treatment policy so that now children with cystic fibrosis whose lungs are colonised with pseudomonas are increasingly being admitted every three months for a 14 day course of intravenous antibiotics. This is rapidly increasing the number of admissions and greatly increasing the cost of treating the disease as the drug is expensive and accounts for about $25 \%$ of the hospital's drug bill. For eczema the high cost is largely attributable to a new regimen of treatment, which includes admission to hospital for eight to 10 weeks and the use of an expensive elemental diet. This study highlights the expense of early development of innovative treatment (in this case for eczema). Some academic clinicians fear that the precise identification of costs by clinical budgeting may impede the early development of innovative treatment or research.

This project meant a minimal contribution of time from the clinician (about three hours over six weeks) and indeed provided data that would otherwise have been unavailable or far too tedious for a clinician to produce. Many of the results were unexpected and thought provoking, and often highlighted aspects of clinical work of which clinicians were unaware. Some led to cost savings. One clinician discovered that the second greatest part of his drug bill, after antibiotics, was intravenous fluids. It had been the practice to use intravenous fluids to prevent thrombosis in intravenous cannulas, and this was stopped in favour of flushing the cannulas with heparinised saline.

\section{Conclusions}

This project shows that budgeting information can be obtained in a form that clinicians can understand and use. The method is a means of relating costs (the treasurer's responsibility) with clinical practice (the doctor's domain). The information could be used either by doctors or by administrators for cost appraisal. In a cash limited environment some doctors fear that this information may be used by administrators to interfere with clinical decisions.

We thank the North Western Regional Health Authority, who seconded a management accountant for part of this study, and $\mathrm{Dr} \mathrm{J} \mathrm{H}$ Keen, Dr I A McKinlay, Dr R W Newton, Mr K A Haines, Mr J Lockwood, and the members of staff at Booth Hall Children's Hospital who helped to provide information.

(Accepted 4 fanuary 1985) 


\section{Management budgeting progress}

Experience in the four demonstration districts where management budgeting has been introduced has been collected in a circular to health authorities from the Department of Health and Social Security. ${ }^{1}$ Based on the advice of the Steering Committee on Management Budgets the circular states that the "overriding objective of introducing management budgeting in the NHS is to enable it to give a better service to its patients, by helping clinicians and other managers to make better informed judgments about how the resources they control can be used to the maximum effect." Four key points are emphasised:

"(a) Management budgeting should not be seen as an accounting exercise, or as a device for containing costs. The key purpose is to improve services through more effective management at local level.

(b) Clinicians, nurse managers, and other budget holders need to be actively involved, and to gain an understanding of their own management role, if the system is to succeed.

"(c) Budget setting and review involve judgments about priorities which need to be integrated with the district priorities through the planning system.

" $(d)$ Although the principles are straightforward, preparing and maintaining budgets involves manipulating a great deal of detailed information. It is essential that the systems established for this purpose are equal to the task, and that the data generated are reliable."

As to the future, the DHSS says that district health authorities need to ensure that two conditions are met. The first is the commitment and enthusiasm of clinicians and other budget holders, and of local management generally. The second is the adequacy of the information systems and their ability to deliver information accurately and on time. The proposals are that during 1985-6 the four demonstration districts will start to demonstrate management budgeting in action so that those in the second generation can draw on their experience in the following year. By 1988-9, after the full introduction of new information systems, all districts should be in a position to involve clinicians and others in the management of their hospital units by means of budgeting.

The steering committee proposes to monitor a limited number of second generation districts-not more than one in any regionand continue to assess and report on experience nationally. The districts selected so far are Huddersfield (Yorkshire); South Lincolnshire (Trent); West Suffolk (East Anglian); Maidstone (South East Thames); Shropshire (West Midlands); Wirral (Mersey); Tameside and Glossop (North Western); Portsmouth (Wessex); and Riverside (North West Thames). The DHSS will make a small contribution from central funds to these and the first four districts in 1985 .

\section{JCC expresses doubts}

At its recent meeting the Joint Consultants Committee discussed management budgeting and was uneasy about recommending its wide month on budget monitoring." Mr Elkington adoption unless it could be shown to benefit thought that that was an underestimation. patients and save money. The Chief Medical

Officer will be told of the committee's reserva- 1 Department of Health and Social Security. Health tions.

The representative on the Steering Committee on Management Budgets, Mr A P J Ross, said that in the four demonstration districts the consultants did not like what they saw. There had been specialty costings for some years in Basingstoke-one of the districtsbut the consultants had now decided to impose a kind of moratorium until it had been decided who was to be the unit manager. Mr Ross referred to the debate at the last meeting of the Central Committee for Hospital Medical Services when representatives from the firms of management consultant firms, which had set up the systems in the four districts, had discussed the procedure (12 January, $\mathrm{p} 175$ ). The committee had been less than enthusiastic in its response.

services management. services management. Management not become the budget holders someone else Treasurers will be appointed for the first time would-for example, the senior nurse or the as members of the area executive team by 1 administrator. But $\mathrm{Mr}$ Maurice Burrows, June. There will not be general managers CCHMS chairman, said that if the system at unit level.

was costing $£ 120000$ to install in each district These requirements are set out in a circula consultants needed to know that savings from the Department of Health and Social would be made.

Services in the province to improve genera

Mr L P Harvey feared that many consultants management in the light of the Griffiths would be blackmailed into holding the budget, report. ${ }^{1}$ Most of the responses to the Departbut they would need to be trained and that ment's consultation letter of April 1984 would take time. Mr Julian Elkington quoted favoured an evolutionary approach that would the following paragraph from the report of have left the existing consensus management the steering committee: "Clinicians and other arrangements at area level virtually intact. budget holders, and unit and district manage- This, however, according to the Department, ment team members will need to be involved would not offer a realistic prospect of achieving in the preparation and monitoring of budgets. the same improvement as would the appointProvided that adequate management account- ment of general managers.

ing support is available, budget holders may The general manager at area level will carry need to spend some six to 10 hours on budget responsibility and will be directly and personpreparation each year (spread over two to three ally accountable to the board for overall months) and some one to two hours each management performance. The circular states

\section{International meeting discusses health care financing}

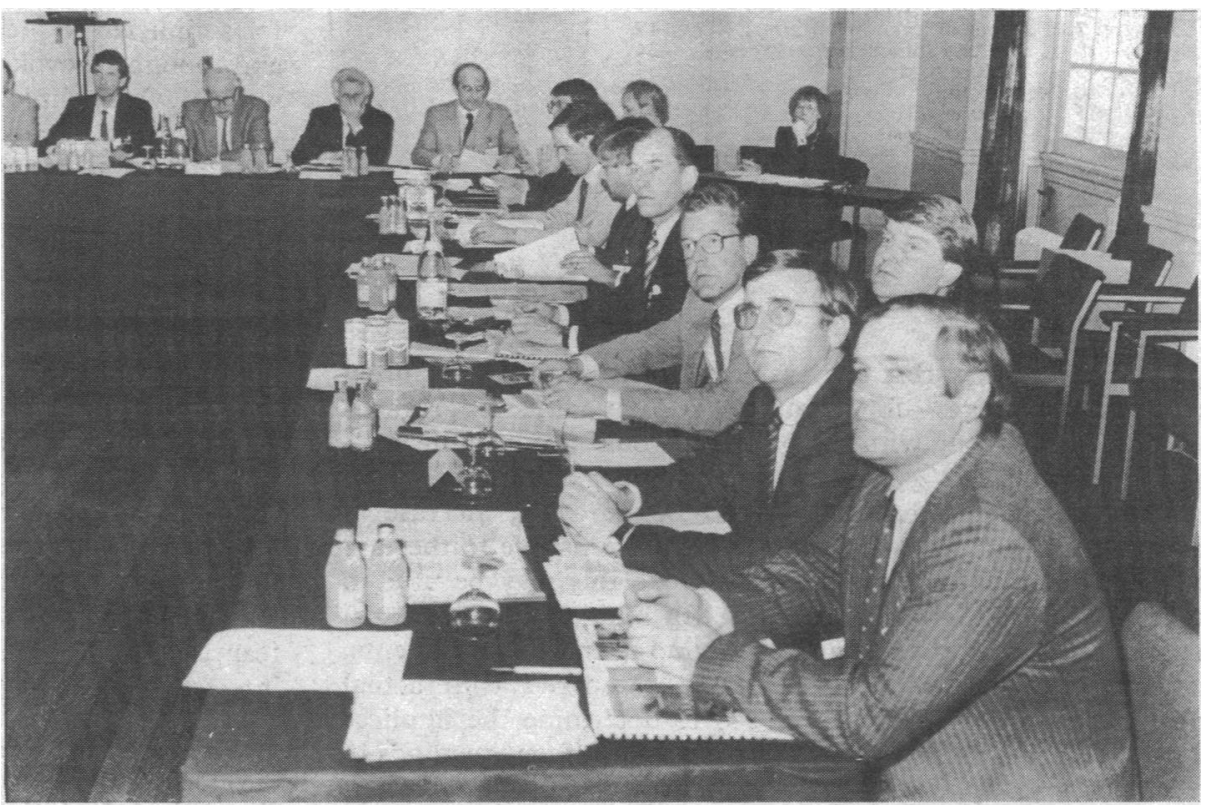

Representatives from the national medical associations in Scandinavia, the Netherlands, Canada, and Ireland, who met representatives of the BMA in London on 15 and 16 February for an informal meeting. The group, which discussed health care financing and public relations, plans to meet annually, and the Danish Medical Association has offered to host a meeting in Copenhagen in 1986. 